\title{
Anti-Proteases and Alpha-1 Antitrypsin Augmentation Therapy
}

\author{
Charlie Strange MD
}

\author{
Introduction and Historical Perspective \\ Proteases and Anti-Proteases \\ Alpha-1 Antitrypsin Deficiency \\ Outcome Measures to Assess Emphysema \\ Treatment for Alpha-1 Antitrypsin Deficiency \\ Alpha-1 Augmentation Therapy \\ Inhaled and Recombinant Alpha-1 Antitrypsin Deficiency Therapy \\ Patient Outcomes and Cost-Effectiveness \\ Other Genotypes of Alpha-1 Antitrypsin Deficiency \\ Lung Transplantation \\ Bronchiectasis \\ Summary
}

\begin{abstract}
Alpha-1 antitrypsin deficiency is a genetic disease that first highlighted the importance of protease balance in normal lung homeostasis. Proteases such as neutrophil elastase are important in many pulmonary diseases. However, the first commercially licensed anti-protease therapy was used for emphysema in alpha-1 antitrypsin deficiency. The 4 commercial alpha-1 protease inhibitor preparations in the United States are currently given intravenously to augment the serum and alveolar epithelial lining fluid concentrations of alpha-1 antitrypsin. Since the discovery of alpha-1 antitrypsin deficiency in 1963, many genetic polymorphisms of the SERPINA1 gene have been discovered. Because neutrophilic inflammation is the hallmark of usual COPD, anti-protease therapy also has been explored in this disease. Further trials with different dosing schema, inhaled therapy, and in different disease states are all ongoing. These studies would be facilitated by having COPD outcomes that are independent of measurement of air flow and achievable in smaller populations over a short period of time. Key words: antitrypsin; alpha-1; emphysema; protease; anti-protease; alpha-1 protease inhibitor; A1PI; alpha-1 antitrypsin deficiency. [Respir Care 2018;63(6):690-698. (C) 2018 Daedalus Enterprises]
\end{abstract}

\section{Introduction and Historical Perspective}

Alpha-1 antitrypsin deficiency is an uncommon genetic disease associated with lung and liver disease. When first

Dr Strange is affiliated with the Division of Pulmonary, Critical Care, Allergy and Sleep Medicine, Department of Medicine, Medical University of South Carolina, Charleston, South Carolina.

Dr Strange has disclosed relationships with Adverum, the Alpha-1 Foundation, Baxalta/Shire, CSL Behring, Grifols, MatRx, the National Institutes of Health, Abeona, AstraZeneca, Bronchus, BTG, CSA Medical, Pulmonx, and Uptake Medical. discovered in $1963,{ }^{1}$ the clinical condition was described as causing emphysema in young individuals. Now, more than 50 years later, we understand much about the biology of alpha-1 antitrypsin, the major serine protease inhibitor in the body. This review will cover how an astute laboratory observation led to major advances in the pathobiology of

Dr Strange presented a version of this paper at the 56th RESPIRATORY CARE Journal Conference, Respiratory Medications for COPD and Adult Asthma: Pharmacologic Actions to Clinical Applications, held June 2223, 2017 in St Petersburg, Florida. 
Table 1. Superfamilies of Proteases and Their Inhibitors

\begin{tabular}{llll}
\hline \hline \multicolumn{1}{c}{ Protease Family } & \multicolumn{1}{c}{$\begin{array}{c}\text { Mechanism of } \\
\text { Protein Destruction }\end{array}$} & $\begin{array}{c}\text { Example Important } \\
\text { in Lung Biology }\end{array}$ & \multicolumn{1}{c}{$\begin{array}{c}\text { Anti-Protease Drugs } \\
\text { Cleared for Human Use }\end{array}$} \\
\hline Serine proteases & Serine alcohol & $\begin{array}{l}\text { Neutrophil elastase } \\
\text { Thrombin }\end{array}$ & $\begin{array}{l}\text { Alpha-1 proteinase inhibitor (A1PI) } \\
\text { Direct thrombin inhibitors, antithrombin III } \\
\text { Cysteine proteases }\end{array}$ \\
$\begin{array}{l}\text { Threonine proteases } \\
\text { Aspartic proteases }\end{array}$ & $\begin{array}{l}\text { Cysteine thiol } \\
\text { Threonine secondary alchohol }\end{array}$ & $\begin{array}{l}\text { Proteosome biology } \\
\text { Cathepsins }\end{array}$ & Multiple myeloma therapy \\
Glutamic proteases & Aspartate carboxylic acid & HIV-1 protease & Antiretroviral therapy \\
Metalloproteases & Glutamate carboxylic acid & MMP-1, MMP-13 & EDTA \\
Asparagine peptide lyases & Metal (usually zinc) & None & \\
& Asparagine to perform an elimination \\
& reaction & & \\
\hline
\end{tabular}

emphysema. The concept that cigarette smoke induced activated neutrophils to transmigrate across endothelial barriers to the lung to excrete the product neutrophil elastase was one of the first real advances in understanding lung biology. The protease/anti-protease balance in the lung remains one of the targets for emphysema therapies to this day.

\section{Proteases and Anti-Proteases}

Proteases are a class of chemicals that degrade proteins into peptides or further into amino acids. Because COPD, including emphysema, is associated with loss of connective tissue proteins in the extracellular matrix, animal models were established in which protease excess was able to cause emphysema. These same animal models were then used to explore the impact of native proteins and pharmaceuticals on matrix degradation. The complexity of biologic proteases that exist in animals, plants, and the microbial world is only now being explored. Recent classifications of proteases have grouped them according to biologic activity rather than along their evolutionary relationships (Table 1).

Although research studies continue in the use of other anti-proteases for lung disease, the remainder of this review will focus on the clinical use and biology of alpha-1 antitrypsin. Alpha-1 antitrypsin was first named because of the ability of this protein to inhibit the enzyme trypsin in the laboratory. Trypsin, a pancreatic enzyme, is not active in lung biology, but was first used in early models of emphysema by intratracheal injection. ${ }^{2}$ On serum protein electrophoresis, the first band produced after albumin

Correspondence: Charlie Strange MD, Division of Pulmonary, Critical Care, Allergy, and Sleep Medicine, Department of Medicine, Medical University of South Carolina, MSC 630, 816 CSB, Charleston, SC 29425. E-mail: strangec@musc.edu.

DOI: $10.4187 /$ respcare. 05933 was named alpha-1. The names alpha- 1 antitrypsin and alpha-1 protease inhibitor were used interchangeably by researchers through the 1970s and 1980s, when there was increasing recognition of the other proteases that could be inhibited by the protein. The name alpha-1 protease inhibitor (A1PI) was advanced with the first drug submissions to the FDA in 1987, and this label has been used in all regulatory filings since. Both names are still used for the protein, although the disease state is uniquely known by its original name, alpha-1 antitrypsin deficiency.

\section{Alpha-1 Antitrypsin Deficiency}

Alpha-1 antitrypsin deficiency is an autosomal co-dominant condition in which one or more abnormal genes are present at the SERPINA1 locus located on chromosome 14q. There is a unique nomenclature that has been derived over 50 years for the condition that began because of abnormal protein detection on electrophoresis. The normal protein is named " $\mathrm{M}$ " because of migration to the middle of the electrophoresis. However, a number of wild-type polymorphisms create normally functioning $\mathrm{M}$ protein. The most common deficiency states result from single amino acid substitutions: valine for glutamate at position 264 (Glu264Val) in the case of S variants and lysine for glutamate at position 342 (Glu342Lys) for $\mathrm{Z}$ variants ${ }^{3}$ are quite common in the United States affecting approximately $4 \%$ of the population. These genes cause a variety of distinct genotypes (eg, protease inhibitor SZ genotype, abbreviated PI*SZ or SZ) with unique characteristics when seen in the homozygous condition or when admixed with the normal $\mathrm{M}$ alleles. Other rare alleles designated QO that cause missense mutations are called null alleles. The propensity for clinical disease is probably defined best by genotypes rather than by single blood level of alpha- 1 antitrypsin, because alpha- 1 antitrypsin is an acute-phase reactant.

Most of the research has been generated in a population of ZZ individuals who have levels of alpha- 1 antitrypsin in 
the blood that are $10-15 \%$ of normal. These individuals will often develop COPD before age 40 if they smoke cigarettes, although the majority of diagnosed cases occur after age $50 .{ }^{4}$ There has historically been a large diagnostic delay between onset of symptoms and the test being performed despite guidelines that recommend testing once in a lifetime for all individuals with COPD. ${ }^{5,6}$ Often this delay has been associated with an alternative diagnosis of asthma $^{7-9}$ that fails to respond appropriately to therapy. ${ }^{10}$ Other significant populations of alpha- 1 antitrypsin deficiency individuals have normal spirometry with advanced emphysema ${ }^{10}$ and abnormalities on chest computed tomography (CT), including bronchiectasis ${ }^{11}$ with or without emphysema. The emphysema is typically of panacinar type, although centrilobular disease can occur. As such, the lower lung zones are usually affected.

When the protease/anti-protease balance of the lung epithelial lining fluid is disrupted by cigarette smoking and/or alpha-1 antitrypsin deficiency, the alveolar structure can be destroyed. Because this probably happens more aggressively when the burden of neutrophils is highest around exacerbations, avoidance of exacerbations is important in alpha- 1 antitrypsin deficiency. At the current time, there is limited information on exacerbations in the alpha- 1 antitrypsin deficiency population, and there are no current recommendations to treat them differently from the usual COPD population.

Neutrophil-mediated airway inflammation that persists after smoking cessation is common to alpha- 1 antitrypsin deficiency and usual COPD. One unique mechanism that may be important in ZZ alpha- 1 antitrypsin deficiency is that the $\mathrm{Z}$ proteins may form polymers with each other inside the hepatocyte and in serum. Polymers of alpha-1 antitrypsin can stimulate influx of lung neutrophils through an interleukin8-dependent mechanism. ${ }^{12,13}$ When added to the impact of neutrophil elastase that stimulates alveolar macrophages to release LTB4, a potent PMN chemoattractant ${ }^{14}$ in a positive feedback loop, most patients with alpha-1 antitrypsin deficiency have a neutrophil-rich lung. Cigarette smoke oxidizes alpha- 1 antitrypsin, and this fact is one rationale behind ensuring smoking cessation before augmentation therapy. This fact has also been important to the usual COPD field, in which oxidation of alpha- 1 antitrypsin in the alveolar microenvironment might be sufficient to induce emphysema in the absence of serum deficiency.

\section{Outcome Measures to Assess Emphysema}

Panacinar emphysema is sometimes difficult to see and differentiate from hyperinflation. Therefore, computer analysis of emphysema severity and distribution has been used to define emphysema-modulating therapies. ${ }^{15} \mathrm{CT}$ density is not highly correlated with traditional measures used in COPD that measure airway function, such as $\mathrm{FEV}_{1}$. A study by Dirksen et al ${ }^{15}$ showed that CT densitometry change required less than one quarter the number of subjects needed to define emphysema progression compared with traditional $\mathrm{FEV}_{1}$ decline, a breakthrough with implications for emphysema research that was acknowledged by the FDA. ${ }^{16}$ This is important because CT density is associated with mortality, ${ }^{17}$ whereas traditional measures of lung function such as $\mathrm{FEV}_{1}$ are not.

Another potential outcome measure is diffusion of the lung for carbon monoxide $\left(\mathrm{D}_{\mathrm{LCO}}\right)$. Historically, $\mathrm{D}_{\mathrm{LCO}}$ has proved difficult to use in clinical trials because of site-tosite and test-to-test variability. However, $\mathrm{D}_{\mathrm{LCO}}$ is usually abnormal, even when spirometry is normal, when significant emphysema is present.

\section{Treatment for Alpha-1 Antitrypsin Deficiency}

The natural history of alpha- 1 antitrypsin deficiency is clearly better when individuals avoid fumes, particulates, and tobacco. Vaccinations against pneumococcal infection and influenza are recommended. Supportive care, including oxygen, antibiotics, bronchodilators, corticosteroids, and pulmonary rehabilitation, are used no differently than in usual COPD. Surgery using lung volume reduction is not recommended in this population, although studies using some new bronchoscopic lung volume reduction options may have promise. Lung transplantation remains an option for this younger population with advanced COPD.

\section{Alpha-1 Augmentation Therapy}

Augmentation of A1PI in severely deficient individuals began at the National Institutes of Health. ${ }^{18}$ Unlike other COPD therapies, A1PI is derived from pooled plasma and thus requires an infrastructure that includes plasma collection from individuals without infectious or malignant diseases. Plasma storage until a second donation occurs from the same plasma donor ensures that no infectious diseases have been acquired and that the plasma is safe to enter the plasma pool. Further testing of the pooled plasma for pathogens is done to ensure safety. No case of acquired infection from A1PI infusion has been published in the subsequent 30 years.

There are 4 A1PI products on the United States market that were all cleared by the FDA on the basis of biochemical parity with Prolastin, the first agent (Aralast, Glassia, Prolastin-C, and Zemaira). In addition to regulatory control of manufacturing processes that differ by drug, infusion into disease-affected subjects was performed to show volume of distribution, serum half-life, and trough serum levels comparable with those of Prolastin. Differences in carbohydrate side chains between products have no known clinical impact. Each new product on the market subse- 


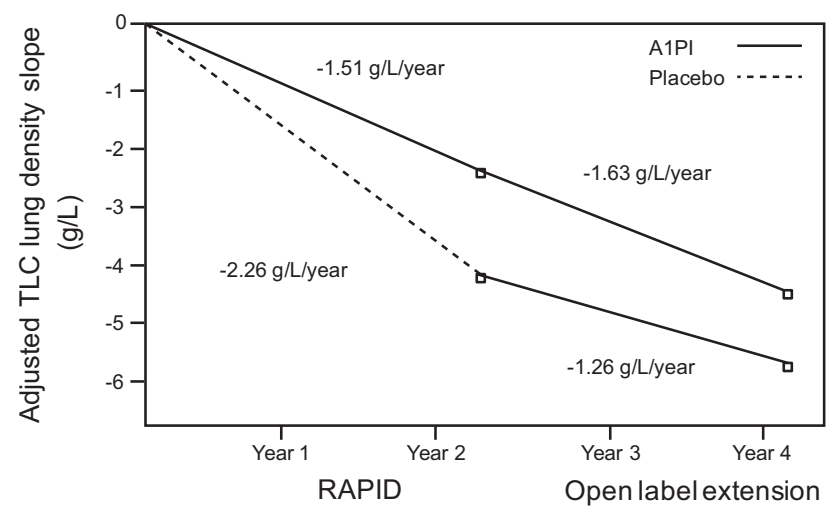

Fig. 1. The intravenous augmentation treatment and lung density in severe alpha-1 antitrypsin deficiency (RAPID) study randomized subjects to intravenous alpha-1 protease inhibitor (A1PI) or placebo for $2 \mathrm{y}$, measuring lung density by percentile density at $15 \%$ at total lung capacity (TLC). The slope of lung density decline was greater in the placebo arm. At $2 \mathrm{y}$, subjects in the placebo arm were transitioned to A1PI in an extension phase of the study. The slope of the placebo group before and after therapy is different. Data from References 22 and 23.

quent to licensure has been required to show clinical efficacy.

In the late 1980s, plasma-purified alpha-1 antitrypsin was safely delivered intravenously to patients with deficiency to achieve plasma levels exceeding a theoretical protective threshold of $11 \mu \mathrm{M}(57 \mathrm{mg} / \mathrm{dL}) .{ }^{19}$ This target concentration was derived from median levels detected in alpha-1 antitrypsin deficiency SZ individuals. The SZ individuals typically do not develop pulmonary disease in the absence of smoking; ${ }^{20}$ thus, it was argued that augmentation to this level is sufficient to protect the lungs from emphysema progression. This threshold is now being reexamined, in part based on data indicating that MZ individuals have an excessive risk of COPD if they smoke. ${ }^{21}$ Regardless of targets chosen during these research studies, there is no clinical benefit to measuring serial blood levels of alpha-1 antitrypsin in patients receiving augmentation therapy because the pharmacokinetics of the drug are relatively stable, and fluctuations reflect transient effects from the role of alpha- 1 antitrypsin as an acute-phase reactant.

Prospective randomized double-blind clinical trials have now shown that emphysema progression is slowed using once-weekly intravenous A1PI at a dose of $60 \mathrm{mg} / \mathrm{kg} .{ }^{22}$ The RAPID study showed that A1PI (Zemaira) slowed the rate of CT density decline over $2 \mathrm{y}$, as measured by the percentile density at $15 \%$ when the CT was taken at total lung capacity. Moreover, the slope of CT density decline, which was fast in the placebo group, returned to a slower decline after open label drug was used for an additional $2 \mathrm{y}^{23}$ (Fig. 1). No secondary outcomes, including $\mathrm{FEV}_{1}$, were affected. Other similar prospective randomized controlled studies are ongo- ing, although the ethics of having a placebo arm have been questioned.

Other observational studies add perspective to augmentation therapy. The NIH Registry enrolled 1,129 individuals at baseline evaluation and followed the majority for $5 \mathrm{y}$ to define the natural history of alpha- 1 antitrypsin deficiency, on or off augmentation therapy. The subset of individuals receiving augmentation therapy with baseline $\mathrm{FEV}_{1}$ values between 31 and $65 \%$ predicted had a smaller loss of $\mathrm{FEV}_{1}$ compared with the $\mathrm{FEV}_{1}$ decline values of subjects not receiving augmentation. More impressively, there was higher mortality in those never receiving augmentation therapy compared with those who did. ${ }^{24}$ This signal was almost exclusively seen in individuals who had a baseline $\mathrm{FEV}_{1}<50 \%$ predicted.

Most of the trials tested the standard dose of $60 \mathrm{mg} / \mathrm{kg}$ administered as a weekly infusion because it maintained the serum levels above the theoretical protective threshold of $11 \mu \mathrm{M} \cdot{ }^{19,25}$ Healthy individuals have levels of alpha-1 antitrypsin that are much higher. Two ongoing trials (NCT01983241 and NCT02722304) are evaluating $120 \mathrm{mg} / \mathrm{kg}$ intravenous weekly doses that produce levels similar to normal. ${ }^{26}$

Adverse events due to therapy have been recorded. The most common of these include chills, urticarial rashes, fatigue, nausea, and vomiting reported in 124 of 58,000 infusions $(0.002 \%) .{ }^{27}$ Because the drugs are manufactured from plasma, small amounts of $\operatorname{IgA}$ can be present. Individuals who are IgA-deficient can have anaphylaxis; therefore, routinely testing a serum IgA level before initiation of therapy is recommended. A rare episode of IgE-mediated anaphylaxis has also been recorded. ${ }^{28}$ First infusions are recommended to be in a supervised setting. The major problems with therapy are intravenous access, infusion burdens, and cost.

\section{Inhaled and Recombinant Alpha-1 Antitrypsin Deficiency Therapy}

Importantly, new attempts at recombinant therapy are ongoing. To date, these have been complicated by intolerance due to allergy from small impurities from the parent cell lines. In addition, recombinant products have shown a shorter half-life once carbohydrate side chains are removed. ${ }^{29-31}$ The advantage of having a recombinant therapy would be lower manufacturing costs compared with the overhead associated with plasma fractionation.

There have also been many studies of inhaled alpha-1 antitrypsin. These have shown high concentrations in epithelial lining fluid and the airways and would allow smaller total doses of drug to be used. Inhaled drug is known to cross into the lung interstitium. ${ }^{32}$ The major problem with this therapy has been that emphysema end points remain extraordinarily expensive to measure over $2-3$ y of any 


\section{Anti-Proteases and Alpha-1 Antitrypsin Augmentation Therapy}

phase-3 clinical trial. However, twice daily inhaled therapy is preferred by patients compared with once weekly intravenous therapy. ${ }^{33}$

\section{Patient Outcomes and Cost-Effectiveness}

Despite anecdotal reports by patients of improved cough, exacerbation frequency, and well-being, these changes in patient reported outcomes have not been shown in randomized controlled trials. Furthermore, cost remains a barrier to performance of A1PI trials in usual COPD. Models measuring cost-effectiveness have estimated a cost per quality adjusted life year of $\$ 59,234$ to $\$ 248,361^{34}$ for the $5-11$ y gained in generated models. ${ }^{35}$

Costs of the infusion can be reduced by self-infusion. Doses $>60 \mathrm{mg} / \mathrm{kg}$ at intervals longer than weekly fail to maintain trough serum levels that are above the theoretical protective threshold ${ }^{36-38}$ and are associated with higher level of variability. ${ }^{39,40}$ Nevertheless, prescription intervals of $120 \mathrm{mg} / \mathrm{kg}$ every 2 weeks are often in use, particularly around travel.

\section{Other Genotypes of Alpha-1 Antitrypsin Deficiency}

Findings that individuals with one copy of the $\mathrm{Z}$ allele (MZ carriers) have an increased risk of emphysema if they have ever smoked have raised the question of whether they should be treated with augmentation therapy. ${ }^{41}$ Because average MZ baseline serum levels ( $\sim 20 \mu \mathrm{M}$, or $\sim 100 \mathrm{mg} / \mathrm{dL})$ are already twice the theoretical protective threshold for $\mathrm{ZZ}$ individuals $(<11 \mu \mathrm{M}$, or $\sim 57 \mathrm{mg} / \mathrm{dL})$, no studies using clinical outcomes have been done. Therefore, there are no objective data to recommend A1PI therapy in MZ individuals despite this frequent practice. ${ }^{41}$

Individuals with other deficiency genotypes also have few studies. Patients with combinations of S, I, QO, or F alleles with a $\mathrm{Z}$ allele are often given augmentation therapy on theoretical grounds. Some SZ individuals have been included in the above randomized trials because approximately $10 \%$ of SZ individuals have serum levels of alpha-1 antitrypsin $<11 \mu \mathrm{M} .{ }^{42}$

\section{Lung Transplantation}

The role for augmentation therapy in the setting of lung transplantation remains controversial..$^{43}$ One argument suggests that A1PI augmentation should not be given because it took many years to develop emphysema severity sufficient to require augmentation. The alternative argument is that there is a high protease burden in lung transplant rejection, and therefore, A1PI in this rare population may improve lung inflammation. A prospective study is ongoing (NCT02614872).

\section{Bronchiectasis}

Airway infections are associated with a large protease burden in individuals with clinically important bronchiectasis. This target has been studied in small cystic fibrosis and alpha-1 antitrypsin deficiency cohorts with inhaled or intraveous A1PI. Bronchiectasis due to Mycobacterium avium complex has been found to be increased in prevalence in MZ genotypes. ${ }^{44}$ However, no studies of augmentation therapy as primary or adjunctive therapy for $M$. avium complex have been performed.

\section{Summary}

Currently available alpha-1 antitrypsin augmentation therapy is burdensome and costly for the community of individuals living with and caring for alpha- 1 antitrypsin deficiency. There is an interest in novel therapies to restore protease/anti-protease balance in the lungs of patients with usual COPD; however, the biomarker outcomes necessary to determine the COPD endotypes likely to benefit have not been developed. Clinical trials in alpha-1 antitrypsin deficiency are difficult to enroll because of disease rarity. In addition, many individuals receiving augmentation therapy decline to stop therapy for placebo-controlled studies. Clinical trials are facilitated in the United States from the Alpha-1 Foundation Research Registry and Alpha Coded Testing Study that are funded by the Alpha-1 Foundation. Cost effectiveness of intravenous augmentation therapy needs to be improved, and aerosol administration is the most likely candidate to achieve this aim if expensive regulatory burdens can be lessened. The current standard of once weekly intraveous augmentation therapy with pooled plasma alpha-1 antitrypsin will continue to define the next decade of specific therapy for alpha- 1 antitrypsin deficiency.

With all of the burdens associated with the disease alpha- 1 antitrypsin deficiency, the focus of the pulmonary community should be to identify affected individuals. By identifying families with this disease, early intervention around cigarette smoking will prevent COPD. Furthermore, more patients identified will lower the costs and burdens of therapy by facilitating the next generation of anti-protease therapies.

\section{REFERENCES}

1. Laurell CB, Eriksson S. The electrophoretic alpha1-globulin pattern of serum in alpha1-antitrypsin deficiency. 1963. COPD 2013; 10(Suppl 1):3-8.

2. Snider GL, Lucey EC, Stone PJ. Animal models of emphysema. Am Rev Respir Dis 1986;133(1):149-169.

3. Curiel DT, Chytil A, Courtney M, Crystal RG. Serum alpha 1-antitrypsin deficiency associated with the common S-type (Glu264Val) mutation results from intracellular degradation of alpha 1-antitrypsin prior to secretion. J Biol Chem 1989;264(18):10477-10486. 


\section{Anti-Proteases and Alpha-1 Antitrypsin Augmentation Therapy}

4. Campos MA, Wanner A, Zhang G, Sandhaus RA. Trends in the diagnosis of symptomatic patients with alpha1-antitrypsin deficiency between 1968 and 2003. Chest 2005;128(3):1179-1186.

5. Global Initiative for Chronic Obstructive Lung Disease. Global strategy for the diagnosis, management, and prevention of chronic obstructive pulmonary disease, Global initiative for chronic obstructive lung disease. Updated 2017. www.goldcopd.org.

6. American Thoracic Society, European Respiratory Society. American Thoracic Society/European Respiratory Society statement: standards for the diagnosis and management of individuals with alpha-1 antitrypsin deficiency. Am J Respir Crit Care Med 2003;168(7):818900.

7. Brantly ML, Paul LD, Miller BH, Falk RT, Wu M, Crystal RG. Clinical features and history of the destructive lung disease associated with alpha-1-antitrypsin deficiency of adults with pulmonary symptoms. Am Rev Respir Dis 1988;138(2):327-336.

8. Tobin MJ, Cook PJ, Hutchison DC. Alpha 1 antitrypsin deficiency: the clinical and physiological features of pulmonary emphysema in subjects homozygous for Pi type Z: a survey by the British Thoracic Association. Br J Dis Chest 1983;77(1):14-27.

9. Janus ED, Phillips NT, Carrell RW. Smoking, lung function, and alpha 1-antitrypsin deficiency. Lancet 1985;1(8421):152-154.

10. Bernspång E, Sveger T, Piitulainen E. Respiratory symptoms and lung function in 30-year-old individuals with alpha-1-antitrypsin deficiency. Respir Med 2007;101(9):1971-1976.

11. Parr DG, Guest PG, Reynolds JH, Dowson LJ, Stockley RA. Prevalence and impact of bronchiectasis in alpha1-antitrypsin deficiency. Am J Respir Crit Care Med 2007;176(12):1215-1221.

12. Bergin DA, Reeves EP, Meleady P, Henry M, McElvaney OJ, Carroll TP, et al. Alpha-1 antitrypsin regulates human neutrophil chemotaxis induced by soluble immune complexes and IL-8. J Clin Investig 2010;120(12):4236-4250.

13. Mahadeva R, Atkinson C, Li Z, Stewart S, Janciauskiene S, Kelley DG, et al. Polymers of $Z$ alpha1-antitrypsin co-localize with neutrophils in emphysematous alveoli and are chemotactic in vivo. Am J Pathol 2005;166(2):377-386.

14. Hubbard RC, Fells G, Gadek J, Pacholok S, Humes J, Crystal RG. Neutrophil accumulation in the lung in alpha 1-antitrypsin deficiency: spontaneous release of leukotriene B4 by alveolar macrophages. J Clin Investig 1991;88(3):891-897.

15. Dirksen A, Dijkman JH, Madsen F, Stoel B, Hutchison DC, Ulrik CS, et al. A randomized clinical trial of alpha(1)-antitrypsin augmentation therapy. Am J Respir Crit Care Med 1999;160(5 Pt 1): 1468-1472.

16. Food and Drug Administration. Proceedings of Meeting of Blood and Plasma Advisory Committee. Rockville, Maryland: Food and Drug Administration; 1998.

17. Dawkins PA, Dowson LJ, Guest PJ, Stockley RA. Predictors of mortality in alpha1-antitrypsin deficiency. Thorax 2003;58(12):10201026.

18. Gadek JE, Klein HG, Holland PV, Crystal RG. Replacement therapy of alpha 1-antitrypsin deficiency. Reversal of protease-antiprotease imbalance within the alveolar structures of PiZ subjects. J Clin Investig 1981;68(5):1158-1165.

19. Wewers MD, Casolaro MA, Sellers SE, Swayze SC, McPhaul KM, Wittes JT, Crystal RG. Replacement therapy for alpha 1-antitrypsin deficiency associated with emphysema. N Engl J Med 1987;316(17): 1055-1062.

20. Seersholm N, Kok-Jensen A. Survival in relation to lung function and smoking cessation in patients with severe hereditary alpha 1-antitrypsin deficiency. Am J Respir Crit Care Med 1995;151(2 Pt 1): 369-373.
21. Molloy K, Hersh CP, Morris VB, Carroll TP, O'Connor CA, Lasky-Su $\mathrm{JA}$, et al. Clarification of the risk of chronic obstructive pulmonary disease in alpha1-antitrypsin deficiency PiMZ heterozygotes. Am J Respir Crit Care Med 2014;189(4):419-427.

22. Chapman KR, Burdon JG, Piitulainen E, Sandhaus RA, Seersholm $\mathrm{N}$, Stocks JM, et al. Intravenous augmentation treatment and lung density in severe alpha1 antitrypsin deficiency (RAPID): a randomised, double-blind, placebo-controlled trial. Lancet 2015; 386(9991):360-368.

23. McElvaney NG, Burdon J, Holmes M, Glanville A, Wark PA, Thompson PJ, et al. Long-term efficacy and safety of alpha1 proteinase inhibitor treatment for emphysema caused by severe alpha1 antitrypsin deficiency: an open-label extension trial (RAPID-OLE). Lancet Respir Med 2017;5(1):51-60.

24. The Alpha-1-Antitrypsin Deficiency Registry Study Group. Survival and FEV1 decline in individuals with severe deficiency of alpha1antitrypsin. Am J Respir Crit Care Med 1998;158(1):49-59.

25. Silverman EK, Sandhaus RA. Clinical practice: alpha1-antitrypsin deficiency. N Engl J Med 2009;360(26):2749-2757.

26. Campos MA, Kueppers F, Stocks JM, Strange C, Chen J, Griffin R, et al. Safety and pharmacokinetics of $120 \mathrm{mg} / \mathrm{kg}$ versus $60 \mathrm{mg} / \mathrm{kg}$ weekly intravenous infusions of alpha-1 proteinase inhibitor in alpha-1 antitrypsin deficiency: a multicenter, randomized, double-blind, crossover study (SPARK). COPD 2013;10(6):687-695.

27. Wencker M, Banik N, Buhl R, Seidel R, Konietzko N. Long-term treatment of alpha1-antitrypsin deficiency-related pulmonary emphysema with human alpha1-antitrypsin. Wissenschaftliche Arbeitsgemeinschaft zur Therapie von Lungenerkrankungen (WATL)-alpha1AT-study group. Eur Respir J 1998;11(2):428-433.

28. Meyer FJ, Wencker M, Teschler H, Steveling H, Sennekamp J, Costabel U, Konietzko N. Acute allergic reaction and demonstration of specific IgE antibodies against alpha-1-protease inhibitor. Eur Respir J 1998;12(4):996-997.

29. Ziomek CA. Commercialization of proteins produced in the mammary gland. Theriogenology 1998;49(1):139-144.

30. Wright G, Carver A, Cottom D, Reeves D, Scott A, Simons P, et al. High level expression of active human alpha-1-antitrypsin in the milk of transgenic sheep. Bio/technology 1991;9(9):830-834.

31. Casolaro MA, Fells G, Wewers M, Pierce JE, Ogushi F, Hubbard R, et al. Augmentation of lung antineutrophil elastase capacity with recombinant human alpha-1-antitrypsin. J Appl Physiol 1987;63(5): 2015-2023.

32. Hubbard RC, McElvaney NG, Sellers SE, Healy JT, Czerski DB, Crystal RG. Recombinant DNA-produced alpha 1-antitrypsin administered by aerosol augments lower respiratory tract antineutrophil elastase defenses in individuals with alpha 1-antitrypsin deficiency. J Clin Investig 1989;84(4):1349-1354.

33. Monk R, Graves M, Williams P, Strange C. Inhaled alpha 1-antitrypsin: gauging patient interest in a new treatment. COPD 2013; 10(4):411-415.

34. Sclar DA, Evans MA, Robison LM, Skaer TL. Alpha1-proteinase inhibitor (human) in the treatment of hereditary emphysema secondary to alpha1-antitrypsin deficiency: number and costs of years of life gained. Clin Drug Investig 2012;32(5):353-360.

35. Gildea TR, Shermock KM, Singer ME, Stoller JK. Cost-effectiveness analysis of augmentation therapy for severe alpha1-antitrypsin deficiency. Am J Respir Crit Care Med 2003;167(10): 1387-1392.

36. Hubbard RC, Sellers S, Czerski D, Stephens L, Crystal RG. Biochemical efficacy and safety of monthly augmentation therapy for alpha 1-antitrypsin deficiency. JAMA 1988;260(9):1259-1264. 


\section{Anti-Proteases and Alpha-1 Antitrypsin Augmentation Therapy}

37. Barker AF, Iwata-Morgan I, Oveson L, Roussel R. Pharmacokinetic study of alpha1-antitrypsin infusion in alpha1-antitrypsin deficiency. Chest 1997;112(3):607-613.

38. Cammarata SK, Stone CL, Carey JL, Eichenhorn MS. Failure to achieve adequate serum levels with monthly replacement therapy in alpha 1-antitrypsin deficiency. Chest 1994;106(2):651-652.

39. Zamora NP, Pla RV, Del Rio PG, Margaleff RJ, Frias FR, Ronsano JB. Intravenous human plasma-derived augmentation therapy in alpha 1-antitrypsin deficiency: from pharmacokinetic analysis to individualizing therapy. Ann Pharmacother 2008;42(5):640-646.

40. Soy D, de la Roza C, Lara B, Esquinas C, Torres A, Miravitlles M. Alpha-1-antitrypsin deficiency: optimal therapeutic regimen based on population pharmacokinetics. Thorax 2006;61(12):1059-1064.

41. Sandhaus RA, Turino G, Stocks J, Strange C, Trapnell BC, Silverman EK, et al. Alpha1-antitrypsin augmentation therapy for
PI*MZ heterozygotes: a cautionary note. Chest 2008;134(4):831834

42. Turino GM, Barker AF, Brantly ML, Cohen AB, Connelly RP, Crystal RG, et al. Clinical features of individuals with PI*SZ phenotype of alpha 1-antitrypsin deficiency. Alpha 1-Antitrypsin Deficiency Registry Study Group. Am J Respir Crit Care Med 1996; 154(6 Pt 1):1718-1725.

43. Trulock EP. Lung transplantation for alpha 1-antitrypsin deficiency emphysema. Chest 1996;110(6 Suppl):284S-294S.

44. Chan ED, Kaminska AM, Gill W, Chmura K, Feldman NE, Bai X, et al. Alpha-1-antitrypsin (alpha-1 antitrypsin) anomalies are associated with lung disease due to rapidly growing mycobacteria and alpha-1 antitrypsin inhibits Mycobacterium abscessus infection of macrophages. Scand J Infect Dis 2007;39(8): 690-696.

\section{Discussion}

Lugogo: That was a great talk. I tried to get a routine alpha- 1 antitrypsin testing program going, and there was significant resistance. It was a free test, the spot test that could be collected in the clinic and sent out. We went through the rigors of getting it cleared in the system, including the ability to order the test within the electronic medical record. In addition, we were able to scan the results into medical records. However, there were a number of our colleagues who would not agree to have patients who came in for routine pulmonary function testing undergo alpha- 1 testing based on a protocol. So, I feel like it's an uphill battle in terms of uptake by general pulmonary, specifically with regard to incorporating routine screening tests like this into our practices. Are there any suggestions perhaps about how to really bring the community along to offer this testing on a routine basis to all people at risk for alpha-1 deficiency?

MacIntyre: Charlie, before you answer that, I'd like to comment on the pushback from clinicians regarding routine screening. I think the pushback comes (and I'm not saying I'm for or against it) from data (or lack thereof) in your presentation. You showed that the FEV decline seems slower and the protease levels get better and, in the very sick patients, you show soft data that you may actually impact mortality. But the vast majority of these patients, they don't know anything is happening to them other than that their numbers are getting better. Don't you think you need some data that say their clinically important outcomes get better? Their exacerbations go down, their hospitalizations decrease, they walk farther, they exercise better, and/or they have better quality-of-life scores in order to sell this product? I think the reason people get concerned about routine screening is they're scared that a patient with COPD with an $\mathrm{FEV}_{1}$ of 0.60 is going to be told they have alpha-1 antitrypsin deficiency and they're going to immediately demand they get this $\$ 100,000 /$ year therapy. I may be getting old, but drugs, especially expensive drugs that are being cleared on numbers only and not real outcomes, really make me nervous. My favorite story has nothing to do with obstructive airways disease, but is from the ARDSNet study. ${ }^{1}$

Williams: I wondered about the same thing. I assume this is a genotypic test, and I don't know anything about the cost, but has it been evaluated, or is there some strategy about testing and follow-up? Have those kinds of things been considered if there is pushback?

Strange: Let's address these separately, because I believe we should really separate making a diagnosis with all the benefits to a family and the therapeutic decision that Neil [MacIntyre] has rightly suggested has modest benefits. Alpha-1 diagnostic testing can be done with an alpha-1 antitrypsin level that costs $\$ 17$ at my Veterans Affairs hospital. How many other ways do we spend $\$ 17$ in COPD care? With that, we're going to identify the SZs and the ZZs with high accuracy, but we're going to miss the MZ carriers. Remember that about $10 \%$ of the patients with COPD in our clinic are carriers and could have brothers, sisters, and other family members affected. We have taken the tactic that gene-based testing-getting the genotype letters associated with your alpha-1 antitrypsin status-is important for the remainder of family testing. But those are $\$ 250$ tests. If the companies weren't offering it for free, we would probably retract back to an alpha-1 antitrypsin level as the right testing strategy. There's no question that there's a linkage between making a diagnosis and getting therapy, and there is some pushback on the basis of, "We don't believe in the therapy; therefore, we shouldn't test," and I really think that is misguided. So, with all of those caveats, we have benefits of getting the diagnosis and the burden of the treatment issue. Those are the strategies the alpha-1 antitrypsin community has been pushing with limited success. There were approximately 500,000 alpha-1 antitrypsin 
tests done in the past 3 years, so we're making some progress. We think there are a lot of patients who are diagnosed with very mild disease and don't get therapy, and that would be the goal. You could tell your kids not to smoke, and you have a reason. There are lots of good reasons not to smoke, but the smoking cessation rates are phenomenal in the alpha- 1 antitrypsin population, objectively studied. We think we can get smoking cessation to occur at a $95 \%$ level, which is much higher than the general population.

MacIntyre: I'm holding your feet to the fire here. You get a patient with COPD, he has stopped smoking, is not particularly symptomatic, has an $\mathrm{FEV}_{1}$ of $50 \%$ of predicted and you do the test on him and he is ZZ. Are you going to treat him? Virtually asymptomatic and the $\mathrm{FEV}_{1}$ is not bad.

Strange: Let me answer that with respect to the CT density issues. CT density has been studied in a large database in the United Kingdom called the ADAPT database that has about 20 years of CT density data. ${ }^{2}$ The authors have shown that the correlates of mortality are not $\mathrm{FEV}_{1}$, and they are not exacerbation frequency. Instead, emphysema density decline matters. Emphysema severity correlates with mortality in the ADAPT database, and very few other things do. In our alpha-1 antitrypsin population, there are few correlations between $\mathrm{FEV}_{1}$, the measure that we all use for many of our usual COPD therapies, and outcomes. Neil is right that we really need to bring it back down to an outcome that matters. The problem here is that the only outcome that we can show good data on is mortality, and its correlate is CT density and not symptoms.

MacIntyre: But you didn't answer my question, are you going to treat this person?
Strange: I do not automatically treat anyone. This is where shared decision making enters the equation. I often follow individuals for a few years and see how they're doing.

MacIntyre: This begs my next question, which is the one that bothers me the most. What do you tell this patient when he says, "I read your papers that this saves lives and why won't you give me this drug?"

Strange: The Alpha-1 Antitrypsin Foundation just put out a statement, and it's on their website, that the available therapies produce modest benefit, and the burdens should not be understated. We did not talk about the burdens, but they include weekly intravenous infusions, the $\$ 100,000$ cost, and who's going to pay for it. I'm happy to go on record that we need better therapies for alpha-1 antitrypsin. We have an expensive drug and a rare disease. If our studies were applied to a larger group of patients, the community might be able to do better studies than the ones we've been limited by cost to do.

Peters: Let me ask you, since we see patients in our lung transplant program who have emphysema who have never smoked: Can someone have an MM genotype who actually has non-functional alpha-1 antitrypsin protease inhibitor? Can we test for it, and do they genetically pass it on?

Strange: In our study of people with alpha-1 antitrypsin deficiency and normal spirometry, about $75 \%$ of them have emphysema on a CT scan. Emphysema precedes spirometric abnormalities. We think some of these people with emphysema should be tested. Right now, because they don't have air-flow obstruction, they don't fit into the diagnosis of COPD. That's a different topic, but we have a lot of symptomatic patients with normal spirometry.
Peters: We saw a patient with MM but who seemed to clinically have alpha-1 antitrypsin disease. Do we test for all genotypes that cause the disorder, and if the test comes back showing MM, how do we know if the protein is functional? What if it's not folded properly and it's not working? Is there a functional assay?

Strange: There are 500 other alleles that have been identified other than the normal $\mathrm{M}$ variants. $\mathrm{S}, \mathrm{Z}, \mathrm{I}$, and $\mathrm{F}$ alleles are the ones currently being tested. Without sequencing the gene, you're not going to test all 500 . We have a functional assay, but these are actually very difficult to perform.

Donohue: What about exacerbations?

Strange: Exacerbations in the alpha-1 antitrypsin population are not very well understood, and just like in the usual COPD population, they're very heterogeneous. Nobody has done large enough cohorts to actually get statistically significant exacerbation signals out of any of the studies that have been done to date. The Kamada study ${ }^{3}$ on inhaled therapy had $<100$ subjects in each arm; it was not a large study. CSL Behring using their product Zemaira in the RAPID study ${ }^{4}$ had more severe exacerbations in the treatment versus the placebo arm, although not a statistically significant number. My bias is that we need to specifically study the anatomy of an exacerbation in alpha- 1 .

Wise: What are your thoughts about neonatal screening for alpha-1? It seems to me that that would make more sense.

Strange: When we talk to the neonatal panel that governs Baby's First Test, they say this is the perfect disease to disease everybody in America at age 10 before they start smoking. Unfortunately, we have no other genetic test that we apply to all 10-yearolds in the United States, so they wanted to develop a whole new paradigm. Alpha- 1 is now cleared for re- 


\section{Anti-Proteases and Alpha-1 Antitrypsin Augmentation Therapy}

porting on 23andme.com, so we get a lot of referrals from them and other test your genes panels. The neonatal tests on average have an assay that costs on the order of $\$ 0.30$. We might be able to get an alpha-1 level down to $\$ 5$. However, we would still need a demonstration project to show that we alter in a meaningful way infantile liver disease presentations or some other important outcome, such as smoking behavior, before it ends up on the panel.

Wise: So right now it's...?

Strange: Right now we are left with the historical Swedish birth testing cohort and results from a small Oregon testing program, and they're the only ones we have.

Rubin: Excellent presentation as always. As a pediatric pulmonologist sitting here, just a quick note that alpha-1 antitrypsin in infants and children is liver disease. And I don't believe they've ever reliably reported on lung disease associated with alpha-1 antitrypsin deficiency in and of itself in children or even in young adolescents.

Strange: We have wondered whether there is an excess allele frequency in asthma; it has not been well studied, and we do not have adequate data to support that hypothesis.

Rubin: And similarly, we wonder whether some of the rapid decliners in cystic fibrosis are due to an excess of neutrophil elastase with or without abnormalities in alpha- 1 protease inhibitor.

Strange: Individuals with genetic abnormalities of both cystic fibrosis transmembrane regulator and alpha-1 have been described.

\section{REFERENCES}

1. Acute Respiratory Distress Syndrome Network, Brower RG, Matthay MA, Morris A, Schoenfeld D, Thompson BT, Wheeler A. Ventilation with lower tidal volumes as compared with traditional tidal volumes for acute lung injury and the acute respiratory distress syndrome. NEngl J Med 2000;342(18): 1301 1308.

2. Green CE, Parr DG, Edgar RG, Stockley RA, Turner AM. Lung density associates with survival in alpha-1 antitrypsin deficient patients. Respir Med 2016;112:8187.

3. Ejiofor SI, Stolk J, Fernandez P, Stockley RA. Patterns and characterization of COPD exacerbations using real-time data collection. Int J Chron Obstruct Pulmon Dis 2017;12: 427-434.

4. Chapman KR, Burdon JG, Piitulainen E, Sandhaus RA, Seersholm N, Stocks JM, et al. Intravenous augmentation treatment and lung density in severe $\alpha 1$ antitrypsin deficiency (RAPID): a randomised, doubleblind, placebo-controlled trial. Lancet 2015;386(9991):360-368

This article is approved for Continuing Respiratory Care Education credit. For information and to obtain your CRCE

(free to AARC members) visit

www.rcjournal.com

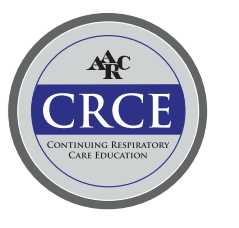

